\title{
The diagnosis of acute appendicitis in pregnant versus non-pregnant women: A comparative study
}

\author{
Abbas Aras ${ }^{1 *}$, Erbil Karaman ${ }^{2}$, ÇaĞhan pekşen ${ }^{3}$, Remzı Kizltana ${ }^{1}$, Mehmet Çetin Kotan ${ }^{4}$ \\ ${ }^{1}$ Assistant Professor, Department of General Surgery, School of Medicine, Yüzüncü Yıl University, Van, Turkey \\ ${ }^{2}$ Assistant Professor, Department of Obstetrics and Gynecology, School of Medicine, Yüzüncü YII University, Van, Turkey \\ ${ }^{3}$ Research Assistant, Department of General Surgery, School of Medicine, Yüzüncü YIl University, Van, Turkey \\ ${ }^{4}$ Professor, Department of General Surgery, School of Medicine, Yüzüncü YII University, Van, Turkey
}

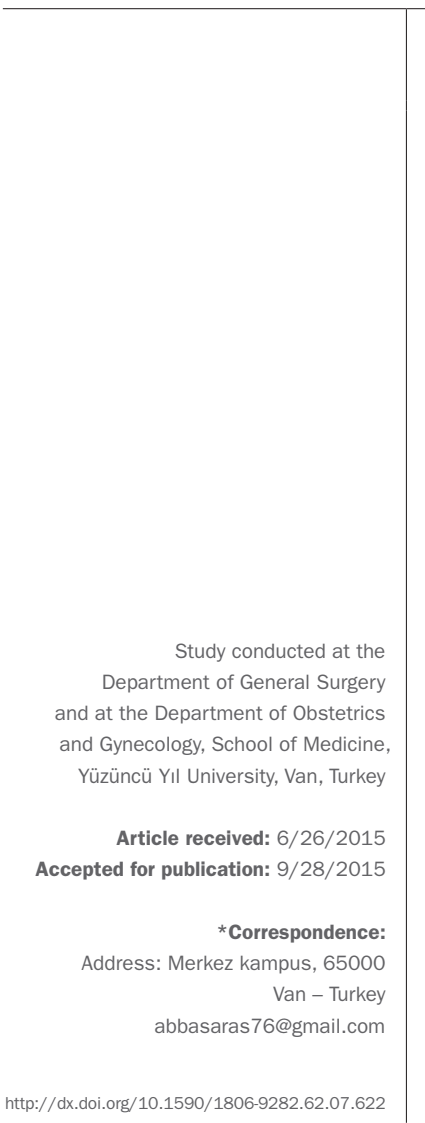

\section{SUMMARY}

Objective: To investigate whether the diagnosis of acute appendicitis is affected by pregnancy or not.

Method: A retrospective study with the analysis of the medical records of all women suspected of having appendicitis who underwent appendectomy at our hospital between June 2010 and March 2015 were reviewed. The patients were divided into two groups according to whether they were pregnant or not during the surgery: group I, pregnant women, and group II, non-pregnant women.

Results: During the study period, 38 pregnant women and 169 non-pregnant women underwent appendectomy. The time from admission to the operation was not statistically different $(2.17 \pm 1.47$ days in group I $v s .1 .98 \pm 1.66$ day in group II; $\mathrm{p}=0.288$ ). The pregnant group had longer hospital stay than the nonpregnant group $(\mathrm{p}=0.04)$. Ultrasonography (USG) was used as the first diagnostic modality in 36/38 patients in group I and 161/169 in group II. The non-visualized appendix on ultrasound was seen in 17 patients in group I and 51 patients in group II, which was not statistically different. Sensitivity and specificity of USG in diagnosis of acute appendicitis were 61.29 and $80.00 \%$ in group I, and 93.0 and $31.6 \%$ in group II, respectively.

Conclusion: Although the diagnosis of appendicitis in pregnant women is not delayed, careful assessment of these patients suspected of having appendicitis should be encouraged when USG examination is normal or nondiagnostic.

Keywords: appendicitis, pregnancy, ultrasonography, diagnosis.

\section{INTRODUCTION}

Appendicitis is the most common non-obstetric surgical emergency during pregnancy, occurring in 1 in 1,000 births reported by a large cohort study including 7,114 pregnant women with appendicitis. ${ }^{1}$ The diagnosis of appendicitis during pregnancy is challenging and it is reported that 25 to $50 \%$ of patients had incorrect preoperative diagnosis for several reasons. ${ }^{2}$ Due to the symptoms and complaints such as nausea, loss of appetite, vomiting, and mild-lower abdominal pain are frequent during the normal pregnancy and also in acute appendicitis, it is reasonable to make efforts to increase and facilitate the early diagnosis and treatment of acute appendicitis. ${ }^{3}$

It has been reported that any delay or misdiagnosis of acute appendicitis will eventually result in perforated or complex appendicitis with peritonitis, which is associated with high rates of early delivery, miscarriage, and fetal loss. ${ }^{4}$ Despite the tendency to late diagnosis of acute appendicitis during pregnancy, it is reported up to $23 \%$ of negative appendectomy rate. ${ }^{5}$ However, a recent study reported that higher rates of adverse obstetric outcomes were observed amongst pregnant women with negative appendectomy. ${ }^{6}$ Ultrasonography (USG) is a non-invasive and inexpensive test, which does not expose the patient to radiation, and is reported to have sensitivity and specificity of 86 and $81 \%$ for the diagnosis of acute appendicitis, respectively. ${ }^{7}$ The major disadvantage of USG is its operator dependent character. There are also speculations that the physiological and anatomical changes due to the gravid uterus within the abdomen make the diagnosis of 
acute appendicitis in pregnant women more difficult than in non-pregnant women. ${ }^{2}$

The purpose of the current study was to investigate whether the diagnosis of appendicitis is affected by pregnancy or not and to evaluate and compare the diagnostic accuracy of USG as an imaging modality in the diagnosis of appendicitis in pregnant and non-pregnant women matched for age and reproductive period.

\section{Method}

This study was conducted in our tertiary referral hospital of Yüzüncü Yil University, School of Medicine, Department of General Surgery after obtaining the institutional ethics committee approval. We retrospectively reviewed and analyzed all the medical files of pregnant women whom underwent appendectomy, either open or laparoscopic, for suspected appendicitis during a 5-year period from June 2010 to March 2015. The data was obtained from our hospital's computer electronic database with the code of surgical operation of appendectomy. The patient demographics, time until hospital admission, applied imaging modalities, laboratory analysis, data regarding surgical interventions including the time from admission to the surgery and intraoperative findings, histological results, postoperative data such as hospital stay were documented. In order to compare the variables, non-pregnant women were used as controls for the pregnant group. The two groups were matched for age and reproductive period. The non-pregnant group comprised women aged between 18 to 45 years, to eliminate the age bias as a confounding variable. The retrospective chart review of non-pregnant women was retrieved from the medical records of women who underwent appendectomy and had a negative pregnancy test during the surgery. The exclusion criteria were women with $<18$ or $>45$ years of age, patients with chronic appendicitis and patients who underwent appendectomy during any intra-abdominal surgery being considered an incidental case.

As a diagnostic imaging modality, the USG was used with graded compression technique and all the results were interpreted by the experienced radiologists. The USG resulted as either diagnosis of appendicitis or normal/ unvisualized (nondiagnostic). The final pathology results were grouped as normal appendix, acute appendicitis and complex appendicitis. Complex appendicitis was defined as any signs of gangrenous, phlegmonous or perforated appendicitis with or without generalized peritonitis. All the surgeries were performed by the senior registrar in the Department of General Surgery under the supervision of consultants. The final diagnosis was accepted as nega- tive appendectomy in case of resected appendix without any histologically proven inflammation.

The main outcome variables were the time of diagnosis from first admission to the operation, negative appendectomy rate and the diagnostic accuracy of USG for appendicitis in pregnant and non-pregnant groups.

The data obtained were analyzed using the Statistical Package for Social Sciences (SPSS) software version 13. Descriptive statistics for constant variables are reported as means \pm standard deviations and range, and categorical variables are reported as numbers (n) and percentages (\%). Mann-Whitney U test and Chi-square test were used for analysis of data between the two groups. The Pearson correlation coefficient was determined for each group to compare the associations between variables. P-value $<0.05$ was considered significant for all statistical analyses.

\section{Results}

A total of 38 pregnant and 169 non-pregnant women who were eligible for the study underwent appendectomy for being suspected of having appendicitis during the 5 -year investigation period in our hospital. During this time, there were 6,540 births in our center and yielding an overall incidence of appendicitis in pregnant women of $0.58 \%$. The mean age of group I (pregnant women) and group II (non-pregnant women) was $27.29 \pm 7.63$ and $28.09 \pm 7.47$, respectively, which was not statistically different. The demographics of the two groups are shown in Table 1. The leukocyte count was statistically higher in the non-pregnant group $(13.88 \pm 5.08)$ than in the pregnant group $(12.94 \pm 4.02)$ $(\mathrm{p}=0.008)$. Of the 38 patients in group I, $32(84.2 \%)$ women had histologically proven appendicitis, of whom 22 (57.9\%) had acute suppurative appendicitis and $10(26.3 \%)$ had complex appendicitis. The negative appendectomy rate in group I was $15.8 \%(n=6)$. In group II, 149 out of 169 non-pregnant women had histologically proven appendicitis with a negative appendectomy rate of $11.8 \%(n=20)$. A hundred and four (104) women in group II had acute appendicitis and 45 women had complex appendicitis. The negative appendectomy rate was not statistically different between the two groups ( $\mathrm{p}=0.796)$. When comparing the histological results of cases with appendicitis within each group, no statistically significant difference was seen with regards to the rate of acute or complex appendicitis between the two groups as shown in Table $1(\mathrm{p}=0.805)$. The ultrasound examination was used as initial diagnostic modality for $36(94.7 \%)$ patients in group I and 161 (95.3\%) in group II. There was a statistically higher rate of non-visualized appendix vermiformis on USG in the pregnant group compared with the non-pregnant group $(\mathrm{p}=0.041)$. When 
examining the USG findings, appendix size greater than 7 $\mathrm{mm}$ was seen in 11 (28.9\%) patients in group I and 88 $(52.1 \%)$ in group II, which was not statistically significantly different $(\mathrm{p}=0.059)$. Also, heterogeneity of mesoappendix detected on USG was seen in $21(58.3 \%)$ women in group I and 109 (67.7\%) in group II, which was also not statistically significantly different $(\mathrm{p}=0.059)$.

As shown in Table 2, the time from admission to the operation was not statistically different between the groups $(\mathrm{p}=0.288)$. There was a statistically lower rate of laparoscopic appendectomy in group I, with 10 (26.3\%) in group I and $91(55.2 \%)$ in group II ( $\mathrm{p}=0.001)$. The majority of pregnant women underwent open (laparotomy) appendectomy (73.7\%). The length of hospital stay was statistically longer in the pregnant group than in the non-pregnant patients $(\mathrm{p}=0.04)$.
The USG findings and histopathologic results of both pregnant and non-pregnant patients were examined and compared. In 20 patients, appendicitis was confirmed histologically, and 19 of those presented acute or complex forms. The sensitivity and specificity of USG in the diagnosis of appendicitis were found to be 61.29 and $80.00 \%$, respectively, in group I. In group II, 145 patients were diagnosed on USG as appendicitis and the histopathology showed 142 out of these 145 patients having an appendix with confirmed inflammation either acute suppurative or complex form. The sensitivity and specificity of USG in group II were 93.0 and $31.6 \%$, respectively. We found that the accuracy rate of USG for diagnosis of acute appendicitis was lower in the pregnant group compared with the non-pregnant group, at 63.86 and $85.7 \%$, respectively (Table 3 ).

TABLE 1 Demographic and diagnostic variables of pregnant and non-pregnant women who underwent appendectomy.

Group I, pregnant

$(\mathrm{N}=38)$

\begin{tabular}{llll}
\hline Age, year (mean \pm SD) & $27.29 \pm 7.63$ & $28.09 \pm 7.47$ & 0.553 \\
\hline Leukocyte count, $\mathbf{x} \mathbf{1 0 3}$ (mean \pm SD) & $12.94 \pm 4.02$ & $13.88 \pm 5.08$ & $\mathbf{0 . 0 0 8}$ \\
\hline USG results & $16(44.4 \%)$ & $16(9.9 \%)$ \\
Non-visualized/normal, $\mathrm{n}(\%)$ & $20(55.5 \%)$ & $145(90.0 \%)$ & \\
Acute appendicitis, $\mathrm{n}(\%)$ & & $109(67.7 \%)$ \\
\hline USG findings & $21(58.3 \%)$ & $51(31.6 \%)$ \\
Heterogeneity of the mesoappendix, $\mathrm{n}(\%)$ & $17(47.2 \%)$ & $22(13.6 \%)$ \\
Non-visualized appendix, $\mathrm{n}(\%)$ & $6(16.6 \%)$ & $88(54.6 \%)$ \\
Appendix size $<7$ mm, $\mathrm{n}(\%)$ & $11(30.5 \%)$ & \\
Appendix size $>7$ mm, $\mathrm{n}(\%)$ & & $20(11.8 \%)$ \\
\hline Pathology results & $6(15.8 \%)$ & $104(61.5 \%)$ \\
Normal, $\mathrm{n}(\%)$ & $22(57.9 \%)$ & $45(26.6 \%)$ \\
Acute appendicitis, $\mathrm{n}(\%)$ & $10(26.3 \%)$ & \\
Complex appendicitis, $\mathrm{n}(\%)$ & & 0.796 \\
\hline
\end{tabular}
Group II, non-pregnant p-value $(\mathrm{N}=169)$

$\mathrm{p}<0.05$ indicates statistical significance; USG: ultrasonography.

P<0.05 indicates steisticalsignificanc; USG: utrasonography.

TABLE 2 Perioperative characteristics of the two groups.

\begin{tabular}{|c|c|c|c|}
\hline & $\begin{array}{l}\text { Group I, pregnant } \\
(\mathrm{N}=38)\end{array}$ & $\begin{array}{l}\text { Group II, non-pregnant } \\
(\mathrm{N}=169)\end{array}$ & p-value \\
\hline Time from admission & & & 0.288 \\
\hline to the operation, days (mean $\pm S D$ ) & $2.13 \pm 1.47$ & $1.98 \pm 1.66$ & \\
\hline Length of hospital stay, days (mean \pm SD) & $3.94 \pm 2.92$ & $2.59 \pm 1.99$ & 0.04 \\
\hline Type of operation & & & 0.001 \\
\hline Laparoscopy, n (\%) & $10(26.3 \%)$ & $91(55.2 \%)$ & \\
\hline Laparotomy, n (\%) & $28(73.7 \%)$ & $78(46.1 \%)$ & \\
\hline Conversion in operation, $\mathrm{n}(\%)$ & 0 & 0 & \\
\hline
\end{tabular}

$\mathrm{p}<0.05$ indicates statistically significant difference. 
TABLE 3 Comparison of diagnostic accuracy of USG for appendicitis in pregnant and non-pregnant women

undergoing appendectomy.

\begin{tabular}{lllllll} 
& & Pregnant (USG) & & \multicolumn{2}{c}{ Non-pregnant (USG) } \\
\hline \multirow{3}{*}{ Pathology } & Normal & Inflammation & Normal & Inflammation & P \\
\cline { 2 - 6 } & Normal & 4 & 1 & 6 & 10 & 132 \\
\cline { 2 - 5 } & Inflammation & 12 & 19 & $85.7 \%$ & \\
\hline & Accuracy & $63.89 \%$ & & 1.0 & \\
\hline & Sensitivity & $61.29 \%$ & & 1.6 & \\
\hline
\end{tabular}

USG: ultrasonography; 1 means appendicitis, 2 means pathologically confirmed appendicitis either acute or complex; $p<0.05$ indicates statistically significance.

\section{Discussion}

Appendectomy for suspected appendicitis is the most commonly performed non-obstetric operation during pregnancy. ${ }^{1}$ It is a well-established data that appendicitis during pregnancy is associated with increasing maternal-fetal mortality and morbidity including fetal loss, abortion, and preterm birth. ${ }^{4}$ The correct diagnosis of appendicitis is challenging and reported to be often inaccurate during pregnancy. ${ }^{8}$ Also, in several recent reports, it was shown that fetal and maternal complications are particularly high in cases with complex appendicitis. ${ }^{1,4}$, So any delay in the timely diagnosis of appendicitis will result in perforated appendicitis with peritonitis, and eventually raise the occurrence of complications. It was reported that pregnancy itself may cause delay in the diagnosis, since physiological and anatomical changes associated with pregnancy may obscure the diagnosis of appendicitis. ${ }^{8}$ In order to explain this, we aimed to investigate pregnant and non-pregnant patients who underwent appendectomy for suspected appendicitis.

It is speculated and reported that the diagnosis of appendicitis during pregnancy is delayed due to several factors such as nausea, vomiting, and loss of appetite, which are common symptoms in both situations; the typical right lower quadrant pain seen with appendicitis, which is obscured during pregnancy due to the shift of the appendix upward and laterally as the uterus grows; and also leukocytosis, which is an important finding of appendicitis and a physiological laboratory finding during pregnancy. ${ }^{10}$ Our findings were not consistent with the literature. ${ }^{4,10}$ In our study, we found that no statistically significant difference in time from first admission to operation was observed between the two groups $(\mathrm{p}=0.288)$. However, in contrast to the literature, the leukocyte count was higher in the non-pregnant group than in the pregnant patients with appendicitis.

It has been reported that USG has a sensitivity and specificity of 86 and $81 \%$ for diagnosing acute appendi- citis in the general population, respectively. ${ }^{7}$ However, its accuracy in pregnant women suspected of having acute appendicitis remains unknown. ${ }^{11}$ In our study, the majority of patients in the two groups underwent USG examination (36/38 in pregnant group and 161/169 in non-pregnant group) and the sensitivity and specificity of USG for detecting acute appendicitis in pregnant and non-pregnant group were 61.2 and $80 \%, 93$ and $31.6 \%$, respectively, which was statistically different. The accuracy of USG to diagnose the appendicitis confirmed by final pathology was $63.8 \%$ among pregnant and $85.7 \%$ among the non-pregnant patients, which was statistically different $(p=0.001)$. So the accuracy of ultrasound is higher in non-pregnant women than pregnant women when diagnosing acute appendicitis. Our results show that when USG was positive for acute appendicitis, no need for further diagnostic test is required; however, if USG is normal or nondiagnostic, further clinical assessment and imaging should be performed. It is reported that USG has a high rate of non-visualization of the appendix during pregnancy. ${ }^{12}$ Similarly, Aggenbach et al. reported, in a study that evaluated 21 pregnant patients who underwent appendectomy, $75 \%$ of non-visualized appendix on USG. ${ }^{13}$ Our result was inconsistent with this study, since we found non-visualized appendix in only $45.7 \%$ of the pregnant patients, less than the previously reported data. However, when comparing the non-visualization of appendix on USG, we observed that it was higher in the pregnant group than in the non-pregnant group, which was statistically significant $(\mathrm{p}=0.01)$. This is possibly related to the altered anatomic location of the appendix, enlarged uterus with viable fetus, obesity, overlying bowel gas, and experience of the operator. ${ }^{8}$

Perforated appendicitis during pregnancy has been reported to increase the risk of maternal mortality and fetal loss. Besides, pregnant women tend to have more perforated appendicitis than non-pregnant ones. ${ }^{14}$ McGory et al., in their study evaluating the impact of negative appen- 
dectomy on the subsequent fetal loss, found that there was no delay in the diagnosis of appendicitis in pregnant women. ${ }^{4}$ Consistent with this data, after excluding women with negative appendicitis, we observed that $26.3 \%$ of the pregnant women had complex appendicitis, compared with $26.6 \%$ of non-pregnant women, indicating that there is no meaningful impact of delay in the diagnosis of appendicitis in pregnant women.

Several studies in the literature have reported that the negative appendectomy rate is high in pregnant women and increases the risk of fetal loss and maternal mortality. ${ }^{4,13} \mathrm{McGory}$ et al. reported a negative appendectomy rate of $23 \%$ in pregnant women compared to $18 \%$ in non-pregnant women $(p<0.05)$. In a study that included 968 women, of which 87 were pregnant, Ito et al. reported that the negative appendectomy rate in the pregnant group was significantly higher than in the non-pregnant group $(36 \%$ vs. $14 \%$; $\mathrm{p}<0.001) .{ }^{15}$ They deduced from the study that negative appendectomy during pregnancy is not free of risk to the fetus. In our study, in contrast to the previous reports, we found a negative appendectomy rate of $15.8 \%$ in the pregnant group and $11.8 \%$ in the non-pregnant group, which was not statistically different $(\mathrm{p}=0.796)$. We think this may be due to the use of high rate of USG examinations before the operation, especially in the pregnant group. Likewise, Wallace et al. compared the negative appendectomy rates among pregnant patients suspected of having appendicitis who were clinically evaluated (54\%), who underwent ultrasonographic evaluation (36\%), and who underwent ultrasound/CT evaluation (8\%). They reported a significant reduction in the negative appendectomy rate in the ultrasound/CT group compared to the clinical evaluation group ( $8 \%$ vs. $54 \%, \mathrm{p}<0.05) .{ }^{16}$

Appendectomy can be performed through laparoscopy or open technique. During the past decades laparoscopic appendectomy has gained wide acceptance for the treatment of acute appendicitis. However, in pregnant women, the use of laparoscopy carries some doubts regarding its feasibility, safety and tolerability. So the choice for surgical approach is possibly dependant on whether the woman is pregnant and on the surgeon's preference. ${ }^{17}$ Cheng et al. stated in a study that laparoscopic appendectomy can be performed safely in pregnant patients without bringing additional maternal complications compared to open appendectomy. ${ }^{18} \mathrm{McGory}$ et al., in a study that included a large number of pregnant women treated with appendectomy $(n=3,133)$, reported laparoscopic appendectomy was performed in 454 (14\%) pregnant patients. They also reported that the fetal loss rate was substantially higher in patients undergoing laparoscopic appen- dectomy $(7 \%)$ than in patients undergoing open $(3 \%)$ appendectomy. ${ }^{4}$ In our study, laparoscopic appendectomy was performed in ten patients in the pregnant group (26.3\%) and 91 patients in non-pregnant group (55.2\%), showing that a majority of pregnant women underwent open appendectomy. Even though the maternal and fetal outcomes were not included in our study's design, unpublished data from our institution comparing the maternal and fetal outcomes of open versus laparoscopic appendectomy in pregnant women including 48 patients showed no differences in fetal loss and maternal complications. Not-surprisingly, the length of hospital stay among pregnant women who underwent appendectomy was statistically longer than among the non-pregnant women $(\mathrm{p}=0.04)$, which may be associated with the evaluation of pregnant women in the obstetric unit with additional medical treatments and, thus, lengthened the hospital stay.

The main limitation of our study is inherent to its retrospective character and the data being reviewed from medical records, which may have some missing points. Also, sample size may limit interpretation of some of the outcomes. Another limitation is that different radiologists evaluated the patients, even though they are all experienced, and multiple pathologists examined the obtained specimens. The strength of our study may be attributed to the fact that it was conducted in a single center, which is a tertiary hospital experienced on these case series.

\section{Conclusion}

In the present study, we found no delay in the diagnosis of appendicitis in pregnant women compared with non-pregnant women. The present study shows that ultrasound examination has a low diagnostic accuracy for acute appendicitis in pregnant women compared with non-pregnant women. In order to avoid any delay in the accurate and timely diagnosis of acute appendicitis in pregnant women, other imaging modalities and further clinical assessments should be kept in mind when USG examination is negative for appendicitis.

\section{ACKNOWLEDGMENTS}

We gratefully thank Professor Sıddık Keskin from Yüzüncü Yil University, Department of Statistics, for his valuable assistance with statistical analyzes.

\section{Resumo}

O diagnóstico de apendicite aguda em mulheres grávidas versus não grávidas: um estudo comparativo 
Objetivo: investigar se o diagnóstico de apendicite aguda é afetado por gravidez ou não.

Método: estudo retrospectivo com análise dos prontuários médicos de todas as mulheres que tiveram suspeita de apendicite $\mathrm{e}$ foram submetidas à apendicectomia em nosso hospital entre junho de 2010 e março de 2015. As pacientes foram divididas em dois grupos, de acordo com a presença de gravidez durante a cirurgia: grupo I, mulheres grávidas; grupo II, mulheres não grávidas.

Resultados: durante o período do estudo, 38 mulheres grávidas e 169 mulheres não grávidas foram submetidas à apendicectomia. $\mathrm{O}$ tempo desde $\mathrm{a}$ internação até $\mathrm{a}$ cirurgia não foi estatisticamente diferente $(2,17 \pm 1,47$ dias no grupo I vs. 1,98 $\pm 1,66$ dia no grupo II, $\mathrm{p}=0,288)$. O grupo das grávidas apresentou uma estadia hospitalar mais longa que o grupo das não grávidas $(\mathrm{p}=0,04)$. A ultrassonografia foi usada como primeira modalidade de diagnóstico em 36/38 pacientes no grupo I e em 161/169 no grupo II. $\mathrm{O}$ apêndice não visualizado na ultrassonografia foi visto em 17 pacientes no grupo I e 51 pacientes no grupo II, e não foi estatisticamente diferente. A sensibilidade e especificidade da ultrassonografia no diagnóstico de apendicite aguda foram 61,29 e $80,00 \%$ no grupo I e 93,0 e 31,6\% no grupo II, respectivamente.

Conclusão: embora o diagnóstico de apendicite em mulheres grávidas não seja protelado, recomenda-se uma avaliação cuidadosa quando o exame de ultrassonografia for normal ou não diagnóstico nessas pacientes.

Palavras-chave: apendicite, gravidez, ultrassonografia, diagnóstico.

\section{References}

1. Abbasi N, Patenaude V, Abenhaim HA. Management and outcomes of acute appendicitis in pregnancy-population-based study of over 7000 cases. BJOG. 2014; 121(12):1509-14.

2. Andersen B, Nielsen TF. Appendicitis in pregnancy: diagnosis, management and complications. Acta Obstet Gynecol Scand. 1999; 78(9):758-62.

3. Firstenberg MS, Malangoni MA. Gastrointestinal surgery during pregnancy. Gastroenterol Clin North Am. 1998; 27(1):73-88.

4. McGory ML, Zingmond DS, Tillou A, Hiatt JR, Ko CY, Cryer HM. Negative appendectomy in pregnant women is associated with a substantial risk of fetal loss. J Am Col Surg. 2007; 205(4):534-40.

5. Berry J, Malt R. Appendicitis near its centenary. Ann Surg. 1984; 200(5):567-75.

6. Agholor K, Omo-Aghoja L, Okonofua F. Rate of negative appendectomy in pregnant women in Benin City, Nigeria. J Obstet Gynaecol Res. 2011; 37(11)1540-8.

7. Terasawa T, Blackmore CC, Bent S, Kohlwes RJ. Systematic review: computed tomography and ultrasound to detect acute appendicitis in adults and adolescents. Ann Intern Med. 2004; 141(7):537-46.

8. Freeland M, King E, Safcsak K, Durham R. Diagnosis of appendicitis in pregnancy. Am J Surg. 2009; 198(6):753-8.

9. Vasireddy A, Atkinson S, Shennan A, Bewley S. Surgical management of appendicitis remains best option during pregnancy. BMJ. 2012; 344:e3575.

10. Tamir IL, Bongard FS, Klein SR. Acute appendicitis in the pregnant patient. Am J Surg. 1990; 160(6):571-5, discussion 575-6.

11. Poortman P, Lohle PN, Shoemaker CM, Oostvogel HJ, Teepen HJ, Zwinderman $\mathrm{KA}$, et al. Comparison of CT and sonography in the diagnosis of acute appendicitis: a blinded prospective study. AJR Am J Roentgenol. 2003; 181(5):1355-9.

12. Lehnert BE, Gross JA, Linnae KF, Moshiri M. Utility of ultrasound for evaluating the appendix during the second and third trimester of pregnancy. Emerg Radiol. 2012; 19(4):293-9.

13. Aggenbach L, Zeeman GG, Cantineau AE, Gordijn SJ, Hofker HS. Impact of appendicitis during pregnancy: no delay in accurate diagnosis and treatment. Int J Surg. 2015; 15:84-9.

14. Tracey M, Fletcher HS. Appendicitis in pregnancy. Am Surg 2000; 66(6):5559; discussion 559-60.

15. Ito $\mathrm{K}$, Ito $\mathrm{H}$, Whang EE, Tavakkolizadeh A. Appendectomy in pregnancy: evaluation of the risks of a negative appendectomy. Am J Surg. 2012; 203(2):145-50.

16. Wallace CA, Petrov MS, Soybel DI, Ferzoco SJ, Ashley SW, Tavakkolizadeh A. Influence of imaging on the negative appendectomy rate in pregnancy. J Gastrointest Surg. 2008; 12(1):46-50.

17. Walsh CA, Tang T, Walsh SR. Laparoscopic versus open appendectomy in pregnancy: a systematic review. Int J Surg. 2008; 6(4):339-44.

18. Cheng HT, Wang YC, Lo HC, Su LT, Soh KS, Tzeng CW, et al. Laparoscopic appendectomy versus open appendectomy in pregnancy: a population-based analysis of maternal outcome. Surg Endosc. 2015; 29(6):1394-9. 